\title{
Active Trigger Points are Associated with Anxiety and Widespread Pressure Pain Sensitivity in Women, but not Men, with Tension Type Headache
}

\section{Authors}

Margarita Cigarán-Méndez ${ }^{\mathbf{1}} \mathrm{PhD}$; Carmen Jiménez-Antona ${ }^{2} \mathrm{PT}, \mathrm{PhD}$; Paula Parás-Bravo ${ }^{3}$ PT, PhD; Stella Fuensalida-Novo ${ }^{2}$ PT, MSc; Jorge Rodríguez-Jiménez ${ }^{2}$ PT, MSc; César Fernández-de-las-Peñas ${ }^{2} \mathrm{PT}, \mathrm{PhD}$, DMSc

\section{Affiliations}

(1) Department of Psychology, Universidad Rey Juan Carlos, Alcorcón, Spain

(2)Department of Physical Therapy, Occupational Therapy, Rehabilitation and Physical Medicine, Universidad Rey Juan Carlos, Alcorcón, Spain

(3) Department of Nursing, Universidad de Cantabria, Spain

\section{Address for reprint requests / corresponding author.}

César Fernández de las Peñas

Facultad de Ciencias de la Salud

Universidad Rey Juan Carlos

Avenida de Atenas s/n

28922 Alcorcón, Madrid

SPAIN

E-mail address: cesar.fernandez@urjc.es
Telephone number: + 34914888884

Fax number: + 34914888957

Keywords: Gender, tension type headache, trigger points, pressure pain.

This article has been accepted for publication and undergone full peer review but has not been through the copyediting, typesetting, pagination and proofreading process, which may lead to differences between this version and the Version of Record. Please cite this article as doi: 10.1111/papr.12775

This article is protected by copyright. All rights reserved. 


\section{Abstract}

Background: A better understanding of gender differences can assist clinicians in further developing therapeutic programs in tension type headache (TTH). Objective: To evaluate gender differences in the presence of trigger points (TrPs) in the head, neck, and shoulder muscles and their relationship with headache features, pressure pain sensitivity, and anxiety in people with TTH. Methods: Two hundred and ten (59 men, 151 women) TTH patients participated. TrPs were bilaterally explored in the temporalis, masseter, suboccipital, upper trapezius, splenius capitis and sternocleidomastoid muscle Headache features were collected with a 4-week headache diary. Trait and state anxiety levels were assessed with State-Trait Anxiety Inventory. Pressure pain thresholds (PPT) over the temporalis, C5/C6 joint, second metacarpal and tibialis anterior were assessed. Results: Women with TTH exhibited a significantly higher number of total $(\mathrm{P}=0.027)$ and active $(\mathrm{P}=0.030)$, but similar number of latent $(\mathrm{P}=0.461)$, TrPs than men with TTH. Active TrPs in the temporalis, suboccipital, and splenius capitis muscles were the most prevalent in both men and women with TTH. The number of active TrPs was associated with anxiety levels $(\mathrm{r}=0.217 ; \mathrm{P}=0.045)$ in women, but not in men $(\mathrm{P}=0.453)$ : the higher the number of active TrPs, the more the trait levels of anxiety. Women exhibited lower PPTs than men (all, $\mathrm{P}<0.001$ ). In men, the number of active, but not latent, TrPs was negatively associated with localized PPTs (all, $\mathrm{P}<0.05$ ), whereas in women, the number of active and latent TrPs was negatively associated with PPTs in all points (all, $\mathrm{P}<0.01$ ): the higher the number of TrPs, the lower the widespread PPTs. Conclusions: This study described gender differences in the presence of $\operatorname{TrP}$ in TTH. Women with "TTH showed lower PPT than men. The association between TrPs, anxiety levels, and pressure pain hyperalgesia seems to be more pronounced in women than in men with TTH.

This article is protected by copyright. All rights reserved. 
Keywords: Gender, tension type headache, trigger points, pressure pain.

\section{Active Trigger Points are Associated with Anxiety and Widespread Pressure Pain Sensitivity in Women, but not Men, with Tension Type Headache}

\section{Introduction}

Tension type headache (TTH) is a common primary headache disorder showing a worldwide point prevalence of $42 \% .^{1}$ In fact, in the Global Burden of Disease Study, headaches were found to be the second most prevalent disorder in the world. ${ }^{2}$ Further, TTH also represents an important burden for the society. ${ }^{3}$ For instance, the general costs in Europe in 2010 were $€ 13.8$ billion for headache, including migraine and TTH. ${ }^{4}$

Current knowledge into the pathogenesis of TTH is mainly focused on the role of muscle tissue and facilitation of nociceptive pain processing. ${ }^{5}$ It is argued that TTH has a muscular component contributing to sensitization process related to the transition from acute to chronic TTH. ${ }^{6,7}$ There is clear evidence suggesting that people with TTH exhibit pressure pain hypersensitivity, i.e., lower pressure pain thresholds, in trigeminal- areas, ${ }^{8}$ cervicalrelated areas, ${ }^{9}$ and distant extra-trigeminal areas ${ }^{10}$ when compared to non-headache sufferers. Similarly, there is also evidence supporting the role of referred pain elicited by muscle trigger points (TrPs) as peripheral contributors to TTH. ${ }^{11} \mathrm{~A}$ TrP is defined as "a hypersensitive spot in taut bands of skeletal muscle which elicit referred pain, autonomic, and motor symptoms when stimulated". ${ }^{12}$ Several studies have found that the referred pain elicited by $\operatorname{TrPs}$ reproduced the pattern pain symptoms in patients with TTH. ${ }^{13}$ In fact, Fernández-de-lasPeñas et al proposed a pain model where the TrPs located in those muscles innervated by the trigeminal or upper cervical nerves would be responsible of prolonged nociceptive afferent 
barrage into the trigeminal nerve nucleus caudalis, sensitizing the central nervous system, and thereby contributing to widespread sensitization found in TTH. ${ }^{14}$ This pain model has been partially confirmed by a recent study reporting that a greater number of TrPs in head, neck and shoulder muscles was associated with widespread pressure pain hypersensitivity in individuals with TTH. ${ }^{15}$ In addition, the number of active TrPs has been also associated with trait anxiety levels, ${ }^{16}$ another factor contributing to central sensitization by reducing the thresholds to noxious input from peri-cranial muscles. ${ }^{17}$

It is important to consider that primary headache, including $\mathrm{TTH}$, exhibit gender differences in their prevalence. ${ }^{18}$ In fact, TTH has a female: male ratio of $3: 1 .^{19}$ Since evidence suggests the presence of gender differences in pain perception, ${ }^{20}$ particularly in sensitivity to pressure pain, ${ }^{21}$ brain structure development and function, ${ }^{22}$ previous life experiences and cultural expectations, ${ }^{23}$ and biopsychosocial factors associated with pain experience, ${ }^{24}$ a better understanding of gender differences in the presence of TrPs in TTH could assist clinicians in determining better therapeutic programs accordingly to gender. Interestingly, it has been previously suggested that headache relationships differ according to gender since sex influences on primary headache phenotype are a complex process and needs examination in a greater number of studies. ${ }^{25}$ However, no study has previously investigated this topic. Therefore, the purpose of this study was to evaluate gender differences in the presence of TrPs in the head, neck, and shoulder musculature and the relationship with clinical features of headache, widespread pressure sensitivity and anxiety levels in men and women with TTH.

This article is protected by copyright. All rights reserved. 


\section{Methods}

\section{Participants}

Patients with headache symptoms were recruited from different university-based hospitals between September 2016 and June 2018. Diagnosis was conducted according to the International Classification of Headache Disorders criteria, third edition ${ }^{26}$ by four experienced neurologists. ${ }^{26}$ To be included, patients had to describe the pain features typical of TTH: bilateral location, pressing/tightening pain, moderate intensity ( $\leq 7$ on a 10-points numerical pain rate scale, NPRS) and no aggravation of headache during routine physical activity. Patients should report neither more than one of photophobia, phonophobia, or nausea and neither moderate nor severe nausea nor vomiting as requested by the ICHD-III diagnostic criteria. $^{26}$

Participants were excluded if presented: 1, other primary or secondary headache including medication overuse headache as defined by the ICHD-III; 2, history of neck or head trauma; 3, history of cervical herniated disk on medical records; 4 , any systemic disease, e.g., rheumatoid arthritis, or lupus erythematous; 5, diagnosis of fibromyalgia syndrome; 6, receiving anesthetic block or physical therapy in the previous 6 months; or, 7, pregnancy. Participants read and signed a consent form prior to their participation. The local Ethics Committee approved the study design (URJC 23/2014, HUFA 14/104).

\section{Headache Diary}

A headache diary for 4 weeks was used to substantiate the diagnosis and to record the headache clinical features. ${ }^{27}$ On this diary, patients registered the number of days with headache (days/week), the headache intensity on an 11-points numerical pain rate scale ${ }^{28}$ (NPRS; 0: no pain, 10: the maximum pain), and the duration of each headache attack (hours/day). 


\section{Trigger point $(\mathrm{TrP})$ examination}

Trigger Points (TrPs) were explored bilaterally in the temporalis, masseter, upper trapezius, suboccipital, sternocleidomastoid and splenius capitis muscles by a clinician with more than 15 years of experience in $\operatorname{TrP}$ diagnosis. The order of examination was randomized between subjects with a 1 min rest period between muscles. The diagnosis was conducted following the updated criteria originally described by Simons et $\mathrm{al}^{13}$ and recommended in a recent Delphi study: $:^{29} 1$, presence of a palpable taut band in a skeletal muscle; 2, presence of a painful spot within the taut band, and, 3, presence of referred pain in response to manual compression. For the suboccipital musculature, the protocol as described by Fernández-de-las-Peñas et al was applied. ${ }^{30}$ In this study, active and latent TrPs were analysed. A TrP was considered active when the referred pain elicited during the examination reproduced, totally or partially, the pain pattern that the subject suffered from during the headache attacks, and, therefore, the pain was recognized as a usual/familiar pain. A TrP was considered latent when the pain elicited during examination did not reproduce any pain feature of the headache, and, therefore, the elicited pain was not recognized as a usual or familiar pain symptom. ${ }^{13,29}$

\section{Widespread Pressure Pain Sensitivity}

Pressure pain threshold (PPT), i.e., the amount of pressure where a sensation of pressure first changes to pain, was also bilaterally assessed with an electronic algometer (Somedic $A B \circledR$, Farsta, Sweden) over the temporalis muscle (trigeminal point), cervical spine (extra-trigeminal point), second metacarpal, and tibialis anterior muscle (two pain-free distant points). The order of assessment was randomized between subjects. Pressure was increased at a rate of approximately $30 \mathrm{kPa} / \mathrm{s}$. Participants were trained with a first trial on the wrist extensors of the right forearm for familiarization of the procedure. The mean of 3 trials on 
each point was calculated and used for the analysis. A 30sec-resting period was allowed between trials for avoiding temporal summation. ${ }^{31}$ The reliability of pressure algometry over these areas has been found to be high. ${ }^{32,33}$ Since no side-to-side differences in PPTs were found, the mean of both sides on each point was used in the main analysis.

\section{State-Trait Anxiety Inventory (STAI)}

The STAI is a 40 items scale assessing the state (items 1-20, STAI-S) as well as trait levels (items 21-40, STAI-T) of anxiety. ${ }^{34}$ The STAI-S items assess relatively enduring symptoms of anxiety. Participants use a 4-points response scale ranging from "not at all" to "very much", to indicate the extent to which they experience each emotion. The STAI-T items assess stable propensity to experience anxiety, and tendencies to perceive stressful situations as threatening. Participants use a 4-points response scale to rate how they generally feel. In both scales, higher scores indicate greater state or trait levels of anxiety. Both scales have shown good internal consistency and high reliability. ${ }^{35}$

\section{Statistical analysis}

Data were analyzed with the SPSS statistical package (22.0 Version). Means and confidence intervals were calculated for all the outcomes by gender. The KolmogorovSmirnov test revealed that all data exhibited a normal distribution $(\mathrm{P}>.05)$. Differences in headache clinical data (i.e., frequency, intensity or duration), anxiety, the number of $\operatorname{TrPs}$ (active or latent TrP) and PPTs between men and women were assessed with the unpaired Student t-test. The chi square $(\chi 2)$ test was used to assess gender differences in the distribution of TrPs (active or latent) for each muscle. The Pearson correlation test (r) was used to determine the associations between the number of active or latent TrPs, anxiety (STAI-S, STAI-T), PPTs, and clinical variables relating to headache (frequency, intensity, duration) in men and women separately. Correlations were considered weak when $\mathrm{r}<0.3$, 
moderate when $0.3<r<0.7$, and strong when $r>0.7 .{ }^{36}$ The statistical analysis was conducted at a $95 \%$ confidence level, and a P-value less than 0.05 was considered statistically significant.

\section{Results}

Two hundred and fifty ( $\mathrm{n}=250)$ subjects with headache were screened for eligibility criteria. Of these, 59 men and 151 women satisfied all the criteria, agreed to participate and signed the informed consent. Forty patients (16\%) were excluded for the following reasons: co-morbid migraine $(n=25)$, previous neck trauma $(n=6)$, medication overuse headache $(n=6)$, and fibromyalgia diagnosis $(n=3)$. Demographic and clinical data are listed in Table 1. No gender differences were observed for clinical data (all, P>.299) except for trait levels of anxiety $(\mathrm{t}=2.419 ; \mathrm{P}=.017)$ : women showed higher trait levels of anxiety than men (Table 1).

\section{Trigger points in men and women with tension type headache}

The mean number of TrPs in the selected and examined muscles for each man with TTH was 5.3 \pm 4.0 (active TrPs: $4.0 \pm 3.3$; latent TrPs: $1.3 \pm 2.0$ ), whereas the number of TrPs on each woman with TTH was $6.5 \pm 3.5$ (active TrP: $5.9 \pm 2.8$, latent TrP: $1.5 \pm 2.3$ ). Women exhibited a significantly higher number of total $(\mathrm{t}=2.231 ; \mathrm{P}=0.027)$ and active $(\mathrm{t}=2.187 ; \mathrm{P}=0.030)$ but similar number of latent $(\mathrm{t}=0.739 ; \mathrm{P}=0.461)$, TrPs than men. The distribution of TrPs in the analyzed musculature was only significantly different for the temporalis and suboccipital muscles between men and women with TTH (both, $\mathrm{P}<0.05$ ) but not for the remaining muscles (all, $\mathrm{P}>0.156$ ): women exhibited a greater proportion of active TrPs in the temporalis and suboccipital muscles than men. Active TrPs in the temporalis, suboccipital, and splenius capitis muscles were the most prevalent in either men or women with TTH (Table 2).

No associations were observed between the number of active TrPs and any clinical pain feature of headache, i.e., intensity, frequency or duration, for either men or women with TTH (all, $\mathrm{P}>0.202$ ). The number of active TrPs was significantly and positively associated with

This article is protected by copyright. All rights reserved. 
trait anxiety levels (STAI-T: $\mathrm{r}=0.217 ; \mathrm{P}=0.045)$ in women, but not in men $(\mathrm{P}=0.453)$ : the higher the number of active TrPs, the more the trait level of anxiety.

\section{Pressure pain sensitivity in men and women with tension type headache}

In general, women exhibited lower PPTs than men in all point (all, $\mathrm{P}<0.001$ ). Table 1 summarizes PPTs of men and women with TTH.

In men with $\mathrm{TTH}$, the number of active, but not latent, TrPs was significantly and negatively associated with PPTs within trigeminal (temporalis: $\mathrm{r}=-0.268, \mathrm{P}=0.042$ ) and extratrigeminal (cervical spine: $\mathrm{r}=-0.337, \mathrm{P}=0.01$ ) points, but not with distant pain-free points (second metacarpal: $\mathrm{r}=-0.157, \mathrm{P}=0.338$; tibialis anterior: $\mathrm{r}=-0.139, \mathrm{P}=0.397$ ): the higher the number of active TrPs, the lower the localized PPTs in the head and neck in men with TTH.

In women, the number of active was significantly and negatively associated with PPTs in all the points (temporalis: $\mathrm{r}=-0.313, \mathrm{P}<0.001$; neck: $\mathrm{r}=-0.210, \mathrm{P}=0.009$; second metacarpal: $\mathrm{r}=-0.256, \mathrm{P}<0.001$; tibialis anterior muscle: $\mathrm{r}=-0.258, \mathrm{P}<0.001)$ : the higher the number of active $\operatorname{Tr}$, the higher the widespread pressure pain sensitivity, i.e., the lower the widespread PPTs. Similar findings were obtained between the number of latent TrPs and PPTs (temporalis muscle: $\mathrm{r}=-0.213, \mathrm{P}=0.008$; cervical spine: $\mathrm{r}=-0.169, \mathrm{P}=0.037$; second metacarpal: $\mathrm{r}=-0.380, \mathrm{P}<0.001$; tibialis anterior muscle: $\mathrm{r}=-0.297, \mathrm{P}<0.001)$ : the higher the number of latent $\operatorname{TrP}$, the higher the widespread pressure pain sensitivity.

\section{Discussion}

This study found that women with TTH exhibited a significantly higher number of active, but similar number of latent, TrPs than men with TTH. The number of active TrPs was weakly associated with anxiety levels and widespread pressure hyperalgesia in women, but not in men with TTH. Our findings suggest the presence of potential gender differences in the role of TrPs between men and women with TTH. 
There is consistent evidence supporting that pain referral elicited by active TrPs reproduces headache features in people with $\mathrm{TTH} ;{ }^{11,13-16}$ however no previous study has investigated if the presence of TrPs is different by gender. The current study is the first one reporting gender differences in the presence of $\operatorname{TrPs}$ and its associations in individuals with TTH. We found that women exhibited higher number of active TrPs and similar number of latent TrPs, than men with TTH. Active TrPs in the temporalis, suboccipital and splenius capitis muscles were the most prevalent in general, however, the proportion of active TrPs in the temporalis and suboccipital muscles was higher in women. A potential underlying mechanism for this finding may be related to sex-related differences in muscle architecture. Animal studies have observed that female rats show greater cross-sectional areas of type I fibers in skeletal muscles, while male rats have more type IIb fibers. ${ }^{37}$ Similarly, human studies reported that men had larger muscle fibers ${ }^{38}$ and more type II muscle fibers than women. ${ }^{39}$ These muscular differences could explain the higher prevalence of myofascial pain syndromes in female. ${ }^{40}$ Nevertheless, other studies have not observed differences in the number and presence of active TrPs between men and women in other conditions, e.g., knee osteoarthritis. $^{41}$ It is possible that some body areas or specific muscles would be more sensitive to this sex-difference.

An interesting finding was the association, although weak, of active TrPs with trait anxiety levels in women, but not men, with TTH. Previous studies have reported that higher levels of anxiety increase the likelihood of muscular tenderness. ${ }^{42,43}$ In fact, general distress is a risk factor for the presence of muscle referred pain. ${ }^{44}$ Therefore, this would support the fact that people with higher levels of trait anxiety also exhibit a greater number of active TrPs; however, that situation was significant in women, but not men, with TTH. There is evidence supporting that anxiety symptoms are more frequent in women than in men (female: male ratio $1.8: 1),{ }^{45}$ which agrees with our results since women with TTH also reported higher 
levels of trait anxiety than men with TTH. Thorn et al. determined that gender differences in response to pain stimulus could be partially attributed to potential disparities in personality traits, i.e., emotional vulnerability, between men and women. ${ }^{46}$ Therefore, biological, cultural, and experiential factors may underlie gender differences on the presence of mood disorders, e.g., anxiety, and its association with pain. ${ }^{47}$

The current study also observed lower PPTs in women with TTH as compared to men which is in agreement with current evidence since there is strong evidence showing that female had greater sensitivity to pressure stimuli than male ${ }^{21}$ and that activation of conditioned pain modulation analgesia is reduced in female than in male. ${ }^{48}$ There are several underlying mechanisms explaining the gender differences in pain perception but their discussion is beyond the scope of this paper. $^{21}$ In addition, we also observed gender differences in the association between the TrPs and pressure pain hyperalgesia since a greater number of active TrPs was weakly associated with higher widespread pressure pain sensitivity in women with TTH, but associated with localized pain sensitivity in men. These results would suggest that the association between active TrPs and pressure pain hyperalgesia previously observed in patients with $\mathrm{TTH}^{49}$ would seem to be more pronounced in women than in men. These associations can suggest that spatial (greater number of) summation of the nociceptive barrage from active TrPs could lead to central sensitization in a more pronounced manner in women than in men with TTH supporting the theoretical pain model proposed by Fernández-de-las-Peñas et al. ${ }^{14}$ Current findings also agree with a study showing that experimental-induced muscle pain is able to inhibit descending pain modulation in female but not in male. ${ }^{48}$ Therefore, anatomical $^{37-39}$ and neurophysiological ${ }^{21}$ gender differences would suggest that muscle pain could be more relevant in women than in men.

This article is protected by copyright. All rights reserved. 
Uncertainty over biological mechanisms withstanding in gender differences, our results have potential clinical implications for the management of patients with $\mathrm{TTH}^{50}$ First, proper identification of active TrPs reproducing the headache symptoms is highly relevant in individuals with TTH; nevertheless, since a greater number of active TrPs is related to higher widespread pressure hypersensitivity, suggesting spatial summation of $\operatorname{TrP}$ activity, in women with TTH, identification of all potential affected muscles maybe highly relevant in women. In fact, there is preliminary evidence suggesting the presence of multiple TrPs in the temporalis muscle in women with $\mathrm{TTH}^{51}$ Therefore, it is possible that clinical presentation of muscle TrPs could be slightly different between women and men with TTH and, hence, carefully clinical examination should be conducted. Second, a recent meta-analysis provided preliminary evidence suggesting that manual treatment of active TrPs may be effective for TTH; however, the quality of evidence was still low because of the presence of few studies and the imprecision of results. ${ }^{52}$ It is possible that the results of our study provide a potential explanation for discrepancies in the effects of $\operatorname{TrP}$ treatment. Since the number of active $\operatorname{TrPs}$ were associated with anxiety levels and widespread pressure pain sensitivity in women, but not in men, with TTH; management of women with TTH should include psychological aspects and central nervous system therapeutic strategies and not just tissue-based (just $\operatorname{TrP}$ manual therapies) interventions.

Although strengths of the current study include a large sample size, the inclusion of patients accordingly the most updated diagnostic criteria, the use of diagnostic diaries and the use of standardized examination procedures; our study has also some potential limitations. First, we included patients referred to a tertiary headache center and thus not representative of the general headache population. Second, the study was cross-sectional and causal relations should not be inferred. Third, TrP diagnosis is still a controversial topic due to lack of golden clinical standards; nevertheless, we conducted a restrictive diagnostic criterion. ${ }^{13,29}$ Finally, 
we did not evaluate socioeconomic status, a factor associated with TTH in women, since women are more susceptible to socioeconomic influences. ${ }^{53}$

\section{Conclusions}

This study found gender differences in the presence of TrPs in TTH. Women with TTH exhibited higher number of active TrPs and lower widespread PPT than men with TTH. Further, the number of active TrPs was weakly associated with anxiety levels and widespread pressure pain hyperalgesia in women but associated with localized pressure pain hyperalgesia in men. Future longitudinal studies will help to determine the clinical implications of these findings.

\section{References}

1. Ferrante T, Manzoni GC, Russo M, Camarda C, Taga A, Veronesi L, Pasquarella C, Sansebastiano G, Torelli P. Prevalence of tension-type headache in adult general population: the PACE study and review of the literature. Neurol Sci 2013; 34: S137-8.

2. GBD 2015 Disease and Injury Incidence and Prevalence Collaborators. Global, regional, and national incidence, prevalence, and years lived with disability for 310 diseases and injuries, 1990-2015: a systematic analysis for the Global Burden of Disease Study 2015. Lancet 2016; 388: 1545-602

3. Dowson A. The burden of headache: global and regional prevalence of headache and its impact. Int J Clin Pract Suppl. 2015; 182: 3-7.

4. Raggi A, Leonardi M. Burden and cost of neurological diseases: a European North-South comparison. Acta Neurol Scand. 2015; 132: 16-22.

5. de Tommaso M, Fernández-de-las-Peñas C. Tension type headache. Curr Rheumatol Rev. 2016; 12: 127-39.

This article is protected by copyright. All rights reserved. 
6. Arendt-Nielsen L, Castaldo M, Mechelli F, Fernández-de-las-Peñas C. Muscle triggers as a possible source of pain in a sub-group of tension type headache patients? Clin J Pain. 2016; 32: 711-8.

7. Bendtsen L, Fernández-de-las-Peñas C. The role of muscles in tension-type headache. Curr Pain Headache Rep. 2011; 15: 451-8.

8. Andersen S, Petersen MW, Svendsen AS, Gazerani P. Pressure pain thresholds assessed over temporalis, masseter, and frontalis muscles in healthy individuals, patients with tension-type headache, and those with migraine: a systematic review. Pain. 2015; 156: $1409-23$.

9. Castien RF, van der Wouden JC, De Hertogh W. Pressure pain thresholds over the craniocervical region in headache: a systematic review and meta-analysis. J Headache Pain. 2018; 19: 9

10. Palacios-Ceña M, Castaldo M, Kelun Wang, Torelli P, Pillastrini P, Fernández-de-lasPeñas C, Arendt-Nielsen L. Widespread pressure pain hypersensitivity is similar in women with frequent episodic and chronic tension-type headache: A blinded case-control study. Headache. 2017; 57: 217-225.

11. Fernández-de-las-Peñas C. Myofascial head pain. Curr Pain Headache Rep. 2015; 19: 28.

12. Simons DG, Travell JG, Simons L. Myofascial pain and dysfunction. The trigger point manual. Third edition. Philadelphia, PA: Wolters Kluwer., 2019.

13. Abboud J, Marchand AA, Sorra K, Descarreaux M. Musculoskeletal physical outcome measures in individuals with tension-type headache: a scoping review. Cephalalgia. 2013; 33: 1319-36.

14. Fernández-de-las-Peñas C, Cuadrado ML, Arendt-Nielsen L, Simons DG, Pareja JA. Myofascial trigger points and sensitization: an updated pain model for tension-type headache. Cephalalgia. 2007; 27: 383-93.

This article is protected by copyright. All rights reserved. 
15. Palacios-Ceña M, Wang K, Castaldo M, Guillem-Mesado A, Ordás-Bandera C, ArendtNielsen L, Fernández-de-Las-Peñas C.Trigger points are associated with widespread pressure pain sensitivity in people with tension-type headache. Cephalalgia. 2018; 38: 237-245.

16. Palacios-Ceña M, Castaldo M, Wang K, Catena A, Torelli $\quad \mathrm{P}$, Arendt-Nielsen L, Fernández-de-las-Peñas C. Relationship of active trigger points with related disability and anxiety in people with tension-type headache. Medicine. 2017; 96: e6548.

17. Cathcart S, Petkov J, Winefield AH, Lushington K, Rolan P. Central mechanisms of stress-induced headache. Cephalalgia. 2010; 30: 285-95.

18. Jarsen R, Stovner LJ. Epidemiology and comorbidity of headache. Lancet Neurol. 2008; 7:354-361.

19. Manzoni GC, Stovner LJ. Epidemiology of headache. Handb Clin Neurol. 2010; 97: 3-22

20. Maurer AJ, Lissounov A, Knezevic I, Candido KD, Knezevic NN. Pain and sex hormones: a review of current understanding. Pain Manag. 2016; 6: 285-96.

21. Racine M, Tousignant-Laflamme Y, Kloda LA, Dion D, Dupuis G, Choinière M. A systematic literature review of 10 years of research on sex/gender and experimental pain perception - Part 1: are there really differences between women and men? Pain. 2012; 153: $602-18$.

22. Ingalhalikar M, Smith A, Parker D, Satterthwaite T, Elliot M, Ruparel K, Hakonarson H, Gur R, Gur R, Verma R. Sex differences in the structural connectome of the human brain. PNAS. 2014; 111: 823-828.

23. Springer K, Stellman J, Jordan-Young R. Beyond a catalogue of differences: a theoretical frame and good practice guidelines for researching sex/gender in human health. Soc Sci Med. 2012; 74: 1817-1824.

This article is protected by copyright. All rights reserved. 
24. Racine M, Tousignant-Laflamme Y, Kloda LA, Dion D, Dupuis G, Choinière M. A systematic literature review of 10 years of research on sex/gender and pain perceptionPart 2: Do biopsychosocial factors alter pain sensitivity differently in women and men? Pain. 2012; 153: 619-635.

25. Fumal A, Schoenen J. Tension-type headache: Current research and clinical management. Lancet Neurology. 2008; 7: 70-83.

26. ICHD-III International Classification of Headache Disorder: Headache Classification Subcommittee of the International Headache Society, 3nd edition. Cephalalgia. 2013; 33: 629-808.

27. Phillip D, Lyngberg AC, Jensen R. Assessment of headache diagnosis: A comparative population study of a clinical interview with a diagnostic headache diary. Cephalalgia. 2007; 27: 1-8.

28. Jensen MP, Turner JA, Romano JM, Fisher L. Comparative reliability and validity of chronic pain intensity measures. Pain. 1999; 83: 157-162.

29. Fernández-de-las-Peñas C, Dommerholt D. International consensus on diagnostic criteria and clinical considerations of myofascial trigger points: A Delphi study. Pain Med. 2018; 19: $142-150$.

30. Fernández-de-las-Peñas C, Alonso-Blanco C, Cuadrado ML, Gerwin RD, Pareja J. Trigger points in the suboccipital muscles and forward head posture in tension type headache. Headache. 2006; 46: 454-60

31. Nie H, Arendt-Nielsen L, Andersen H, Graven-Nielsen T. Temporal summation of pain evoked by mechanical stimulation in deep and superficial tissue. J Pain. 2005; 6: 348-355.

32. Walton DM, Macdermid JC, Nielson W, Teasell RW, Chiasson M, Brown L. Reliability, standard error, and minimum detectable change of clinical pressure pain threshold testing in people with and without acute neck pain. J Orthop Sports Phys Ther. 2011; 41: 644-50.

This article is protected by copyright. All rights reserved. 
33. Chesterson LS, Sim J, Wright CC, Foster NE. Inter-rater reliability of algometry in measuring pressure pain thresholds in healthy humans, using multiple raters. Clin J Pain. 2007; 23: 760-6.

34. Spielberger CD. Manual for the State-Trait Anxiety Inventory STAI (Form Y). Palo Alto, CA: Mind Garden; 1983.

35. Barnes LLB, Harp D, Jung WS. Reliability generalization of scores on the Spielberger State-Trait Anxiety Inventory Educ Psychol Meas. 2002; 62: 603-618.

36. Dancey CP, Reidy J. Statistics without maths for psychology: Using SPSS for Windows. New York: Prentice Hall; 2004.

37. Fox J, Garber P, Hoffman M, Johnson D, Schaefer P, Vien J, Zeaton C, Thompson LV. Morphological characteristics of skeletal muscles in relation to gender. Aging Clin Exp Res. 2003; 15: 264-269.

38. Toft I, Lindal S, Bonaa KH, Jenssen T. Quantitative measurement of muscle fiber composition in a normal population. Muscle Nerve. 2003; 28: 101-108.

39. Tuxen A, Bakke M, Pinholt EM. Comparative data from young men and women on masseter muscle fibres, function and facial morphology. Arch Oral Biol. 1999; 44: 509518.

40. Fillingim RB, King CD, Ribeiro-Dasilva MC, Rahim-Williams B, Riley JL, 3rd. Sex, gender, and pain: a review of recent clinical and experimental findings. J Pain 2009; 10: 447-485.

This article is protected by copyright. All rights reserved. 
41. Sánchez-Romero EA, Pecos-Martín D, Calvo-Lobo C, García-Jiménez D, Ochoa-Sáez V, Burgos-Caballero V, Fernández-Carnero J. Clinical features and myofascial pain syndrome in older adults with knee osteoarthritis by sexand age distribution: A crosssectional study. Knee. 2018 Dec 6. pii: S0968-0160(18)30524-6.

42. Mongini F, Ciccone G, Ceccarelli M, Baldi I, Ferrero L. Muscle tenderness in different types of facial pain and its relation to anxiety and depression: a cross-sectional study on 649 patients. Pain. 2007; 13: 106-111.

43. Vedolin GM, LobatoVV, ContiPCR, Lauris JRP. The impact of stress and anxiety on the pressure pain threshold of myofascial pain patients J Oral Rehabil. 2009; 36: 313-321.

44. Lee JE, Watson D, Frey-Law LA. Psychological factors predict local and referred experimental muscle pain: a cluster analysis in healthy adults. Eur J Pain 2013; 17: 90315.

45. Lampl C, Thomas H, Tassorelli C, Katsarava Z, Laínez JL, Lantéri-Minet M, Rastenyte D, Ruiz de la Torre E, Stovner LJ, Andrée C, Steiner TJ. Headache, depression and anxiety: associations in the Eurolight project. J Headache Pain. 2016; 17: 59.

46. Thorn BE, Clements KL, Ward LC, Dixon KE, Kersh BC, Boothby JL, Chaplin WF. Personality factors in the explanation of sex differences in pain catastrophizing and response to experimental pain. Clin J Pain. 2004; 20: 275-82.

47. Altemus M, Sarvaiya N, Neill Epperson C. Sex differences in anxiety and depression clinical perspectives. Front Neuroendocrinol. 2014; 35: 320-30.

48. Arendt-Nielsen L, Sluka KA, Nie HL. Experimental muscle pain impairs descending inhibition. Pain. 2008; 140: 465-71.

49. Fernández-de-las-Peñas C, Arendt-Nielsen L. Improving understanding of trigger points and widespread pressure pain sensitivity in tension-type headache patients: clinical implications. Expert Rev Neurother. 2017; 17: 933-939.

This article is protected by copyright. All rights reserved. 
50. Paller CJ, Campbell C, Edwards R, Dobs A. Sex-based differences in pain perception and treatment. Pain Med. 2009; 10: 289-299.

51. Fernández-de-las-Peñas C, Caminero AB, Madeleine P, Guillem-Mesado A, Ge HY, Arendt-Nielsen L, Pareja JA. Multiple active myofascial trigger points and pressure pain sensitivity maps in the temporalis muscle are related in women with chronic tension type headache. Clin J Pain. 2009; 25: 506-12.

52. Falsiroli Maistrello L, Geri T, Gianola S, Zaninetti M, Testa M. Effectiveness of trigger point manual treatment on the frequency, intensity, and duration of attacks in primary headaches: A systematic review and meta-analysis of Randomized Controlled Trials. Front Neurol. 2018; 9: 254.

53. Chu MK, Kim DW, Kim BK, Kim JM, Jang TW, Park JW, Lee KS, Cho SJ. Genderspecific influence of socioeconomic status on the prevalence of migraine and tension-type headache: the results from the Korean Headache Survey. J Headache Pain. 2013; 14: 82.

This article is protected by copyright. All rights reserved. 
Table 1: Clinical and demographic characteristics of patients by gender

\begin{tabular}{|c|c|c|c|c|}
\hline & \multicolumn{2}{|c|}{$\operatorname{Men}(n=59)$} & \multicolumn{2}{|c|}{ Women $(n=151)$} \\
\hline & Mean & $95 \% \mathrm{CI}$ & Mean & $95 \% \mathrm{CI}$ \\
\hline \multicolumn{5}{|c|}{ Clinical Data } \\
\hline CTTH/FETTH & \multicolumn{2}{|c|}{$30 / 29$} & \multicolumn{2}{|c|}{$77 / 74$} \\
\hline Age (years) & 44 & $41-47$ & 45 & $42-48$ \\
\hline \multicolumn{5}{|c|}{ Headache Pain Characteristics } \\
\hline Time of onset (years) & 11.2 & $8.2-13.2$ & 10.3 & $8.0-12.6$ \\
\hline Frequency (days/month) & 15.5 & $11.4-19.6$ & 15.5 & $11.8-19.2$ \\
\hline Intensity (NPRS, 0-10) & 6.1 & $5.7-6.5$ & 6.0 & $5.7-6.3$ \\
\hline Duration (hours/day) & 7.4 & $6.1-8.7$ & 7.4 & $6.6-8.2$ \\
\hline Prophylactic treatment (Y/N) & & & & \\
\hline \multicolumn{5}{|c|}{ Psychological Outcomes } \\
\hline STAI-S (state, 0-60) & 21.6 & $19.8-23.4$ & 21.7 & $20.6-22.8$ \\
\hline STAI-T (trait, 0-60)* & 21.4 & $19.0-23.8$ & 24.5 & $23.2-26.8$ \\
\hline \multicolumn{5}{|c|}{ Psychophysical Outcomes } \\
\hline PPT cervical spine $(\mathbf{k P a}) \#$ & 311.0 & $265.0-357.0$ & 194.0 & $178.0-210.0$ \\
\hline PPT temporalis muscle (kPa)\# & 263.5 & $235.0-292.0$ & 193.5 & $180.5-206.5$ \\
\hline PPT second metacarpal (kPa)\# & 322.5 & $291.5-353.5$ & 232.0 & $208.0-256.0$ \\
\hline PPT tibialis anterior (kPa)\# & 505.0 & $418.5-591.5$ & 353.5 & $330.0-377.0$ \\
\hline
\end{tabular}

* Significant differences between women and men with tension type headache $(\mathrm{P}<0.05)$;

\# Significant differences between women and men with tension type headache $(\mathrm{P}<0.001)$;

CTTH: Chronic Tension Type Headache; FEETH: Frequent Episodic Tension Type Headache; STAI: State-Trait Anxiety Inventory; PPT: Pressure Pain Thresholds 
Table 2: Distribution of active and latent trigger points (TrPs) by gender

\begin{tabular}{|c|c|c|c|c|c|c|}
\hline & \multicolumn{2}{|c|}{ Temporalis in men $(n=59) *$} & \multicolumn{2}{|c|}{ Masseter in men $(\mathbf{n}=59)$} & \multicolumn{2}{|c|}{ Sternocleidomastoid in men $(n=59)$} \\
\hline & Right Side & Left Side & Right Side & Left Side & Right Side & Left Side \\
\hline Active TrPs n (\%) & $27(46 \%)$ & $29(49 \%)$ & $16(27 \%)$ & $16(27 \%)$ & $16(27 \%)$ & $19(33 \%)$ \\
\hline Latent TrPs n (\%) & $11(18 \%)$ & $10(17 \%)$ & $9(15 \%)$ & $10(17 \%)$ & $12(21 \%)$ & $9(15 \%)$ \\
\hline \multirow{3}{*}{ No TrPs n (\%) } & $21(36 \%)$ & $20(34 \%)$ & $34(58 \%)$ & $33(56 \%)$ & $31(52 \%)$ & $31(52 \%)$ \\
\hline & \multicolumn{2}{|c|}{ Temporalis in women $(n=151)^{*}$} & \multicolumn{2}{|c|}{ Masseter in women $(n=151)$} & \multicolumn{2}{|c|}{ Sternocleidomastoid in women $(n=151$} \\
\hline & Right Side & Left Side & Right Side & Left Side & Right Side & Left Side \\
\hline Active TrPs n (\%) & $100(66 \%)$ & $99(65.5 \%)$ & $50(33 \%)$ & $41(27 \%)$ & $50(33 \%)$ & $48(31.5 \%)$ \\
\hline Latent TrPs n (\%) & $22(14 \%)$ & $18(12 \%)$ & $28(18.5 \%)$ & $32(21 \%)$ & $40(26.5 \%)$ & $40(26.5 \%)$ \\
\hline \multirow[t]{3}{*}{ No TrPs n (\%) } & $30(20 \%)$ & $34(22.5 \%)$ & $73(48.5 \%)$ & $78(52 \%)$ & $61(40.5 \%)$ & $63(42 \%)$ \\
\hline & \multicolumn{2}{|c|}{ Upper trapezius in men $(n=59)$} & \multicolumn{2}{|c|}{ Splenius capitis in men $(n=59)$} & \multicolumn{2}{|c|}{ Suboccipital in men $(n=59) *$} \\
\hline & Right Side & Left Side & Right Side & Left Side & \multicolumn{2}{|c|}{ Bilateral } \\
\hline Active TrPs n (\%) & $20(34 \%)$ & $18(31 \%)$ & $25(43 \%)$ & $27(46 \%)$ & \multicolumn{2}{|c|}{$25(42 \%)$} \\
\hline Latent TrPs n (\%) & $10(17 \%)$ & $6(10 \%)$ & $4(7 \%)$ & $3(5 \%)$ & \multicolumn{2}{|c|}{$6(10 \%)$} \\
\hline \multirow[t]{3}{*}{ No TrPs n (\%) } & $29(49 \%)$ & $35(59 \%)$ & $30(50 \%)$ & $29(49 \%)$ & \multicolumn{2}{|c|}{$28(48 \%)$} \\
\hline & \multicolumn{2}{|c|}{ Upper trapezius in women $(n=151)$} & \multicolumn{2}{|c|}{ Splenius capitis in women $(n=151)$} & \multicolumn{2}{|c|}{ Suboccipital in women $(n=151)^{*}$} \\
\hline & Right Side & Left Side & Right Side & Left Side & \multicolumn{2}{|c|}{ Bilateral } \\
\hline Active TrPs n (\%) & $69(46 \%)$ & $65(43 \%)$ & $81(54 \%)$ & $87(57 \%)$ & \multicolumn{2}{|c|}{$96(63.5 \%)$} \\
\hline Latent TrPs n (\%) & $22(14.5 \%)$ & $17(11 \%)$ & $14(9 \%)$ & $9(6 \%)$ & \multicolumn{2}{|c|}{$16(10.5 \%)$} \\
\hline No TrPs n (\%) & $60(39.5 \%)$ & $69(46 \%)$ & $57(37 \%)$ & $56(37 \%)$ & \multicolumn{2}{|c|}{$39(26 \%)$} \\
\hline
\end{tabular}

* Significant differences between women and men with tension type headache $(\mathrm{P}<0.05)$ 